\title{
The MeNT-OS Score for Orthopaedic Surgery: An Objective Scoring System for Prioritisation of Orthopaedic Elective Surgeries During a Pandemic
}

\author{
Sumanth Madhusudan Prabhakar ${ }^{1}$ [D $\cdot$ Joshua Decruz ${ }^{1} \cdot$ Remesh Kunnasegaran $^{1}$
}

Received: 20 December 2020 / Accepted: 10 March 2021 / Published online: 29 March 2021

(c) Indian Orthopaedics Association 2021

\begin{abstract}
Introduction The reintroduction of elective Orthopaedic surgery during the COVID-19 pandemic is likely to occur in phases, dictated by resource limitations and loco-regional pandemic status. Guidelines providing a general framework for the prioritisation of surgery have largely been based on surgical urgency, while scoring systems such as the MeNTS score may have limited applicability in the setting of Orthopaedic Surgery. We, therefore, propose an Orthopaedic-specific algorithm ('MeNT-OS'), based on a modification of the MeNTS scoring system, that may be used to objectively triage and prioritise Orthopaedic cases during the COVID-19 pandemic.

Methods We developed a scoring algorithm modified from the Medically Necessary Time-Sensitive Procedure (MeNTS) score with 13 unique variables, reflecting human and physical resource utilisation, surgical complexity, functional status of patients, as well as COVID-19 transmission risk. This score was then trialled in a sample of 118 cases, comprising 69 completed and 49 postponed cases. A higher overall score was intended to correlate with lower surgical prioritisation.

Results The use of our scoring system resulted in higher average scores for postponed cases compared to completed cases, as well as higher median, 25th and 75th percentile scores. These results were statistically significant and showed concordance with the ad hoc decisions made before the scoring system was used, with the lower scores for completed cases suggesting a more favourable risk-benefit ratio for being performed as compared to the postponed cases.

Conclusion The utility of the proposed 'MeNT-OS' scoring system has been assessed using data from our institution and offers an objective and systematic approach that is geared towards Orthopaedic procedures. We believe this scoring tool can provide Orthopaedic surgeons a safe and equitable approach to making difficult decisions on prioritisation of surgery during the COVID-19 period, and possibly other resource-limited settings in the future.
\end{abstract}

Keywords COVID $\cdot$ Triage $\cdot$ Algorithm $\cdot$ Arthroplasty $\cdot$ Pandemic

\section{Introduction}

The global COVID-19 pandemic has caused a paradigm shift on the delivery of surgical care worldwide, with a large proportion of non-emergency or elective surgeries deferred to divert our limited healthcare resources to deal with the pandemic [1]. Orthopaedic procedures have been among the most disrupted aspects of surgical care, causing a significant

Sumanth Madhusudan Prabhakar

sumanthmpr@gmail.com

1 Department of Orthopaedic Surgery, Tan Tock Seng Hospital, 11 Jalan Tan Tock Seng, Singapore 308433, Singapore number of patients to experience profound impacts on their functionality and overall quality of life [2].

As the COVID-19 pandemic continues to evolve, and countries begin gradually easing restrictions on elective surgeries in accordance with the local circumstances, plans for the resumption of elective surgeries are being made [3]. As the reintroduction of elective surgery is likely to occur in a phased manner, accounting for limitations in re-deployment of skilled manpower, availability of consumables for surgery, and other limited healthcare resources, it is likely that a return to pre-pandemic levels of surgical services may not be as quick as initially anticipated [4]. To this end, a number of guidelines for prioritisation of surgery have been issued by professional surgical societies, including the American College of Surgeons [5] (ACS) and the Royal College of 
Surgeons [6] (RCS). However, while these guidelines offer a broad framework for the prioritisation of cases, based on surgical urgency, they often do not account for multiple other dynamic factors which may influence scheduling of surgery.

The Medically Necessary, Time-Sensitive (MeNTS) tool [7] proposed by the University of Chicago is a comprehensive scoring tool that suggests prioritisation of cases based on a detailed consideration of procedure, disease, and patient-related variables (Fig. 1). However, this tool is based on a structure that does not include Orthopaedic specialtyspecific criteria or a consideration of functional status. It includes variables that are difficult to quantify objectively, and contains variables that may be more relevant to general surgery and other non-Orthopaedic surgical specialties. In addition, there has been no validation of the MeNTS scoring for Orthopaedic cases to date.

The use of a scoring system with variables unique to Orthopaedic surgery should allow for more objective prioritisation of Orthopaedic procedures. We, therefore, propose an Orthopaedic-specific algorithm, based on a modification of the MeNTS scoring system, that may be used to objectively triage and prioritise Orthopaedic cases during the COVID-19 pandemic. To our knowledge, this is the first tool designed specifically for use in the context of Orthopaedic surgery.

Table 1. Procedure Factors

\begin{tabular}{llcccc}
\hline Variable & \multicolumn{1}{c}{$\mathbf{1}$} & $\mathbf{2}$ & $\mathbf{3}$ & $\mathbf{4}$ & $\mathbf{5}$ \\
\hline OR time, min & $<30$ & $31-60$ & $61-120$ & $121-180$ & $\geq 181$ \\
\hline Estimated LOS & Outpatient & $<23 \mathrm{~h}$ & $24-48 \mathrm{~h}$ & $2-3 \mathrm{~d}$ & $\geq 4 \mathrm{~d}$ \\
\hline Postoperative ICU need, \% & Very unlikely & $<5$ & $5-10$ & $11-25$ & $>25$ \\
\hline Anticipated blood loss, cc & $<100$ & $100-250$ & $250-500$ & $500-750$ & $\geq 751$ \\
\hline Surgical team size, $\mathbf{n}$ & 1 & 2 & 3 & 4 & $>4$ \\
\hline Intubation probability, \% & $\leq 1$ & $1-5$ & $6-10$ & $11-25$ & $>25$ \\
\hline $\begin{array}{l}\text { Surgical site } \\
\text { None of the } \\
\text { following } \\
\text { row variables }\end{array}$ & Abdominopelvic MIS & $\begin{array}{c}\text { Abdominopelvic } \\
\text { open surgery, } \\
\text { infraumbilical }\end{array}$ & $\begin{array}{c}\text { Abdominopelvic open } \\
\text { surgery, } \\
\text { supraumbilical }\end{array}$ & $\begin{array}{c}\text { OHNS/upper } \\
\text { GI/thoracic }\end{array}$ \\
\hline
\end{tabular}

GI, gastrointestinal; LOS, length of stay; MIS, minimally invasive surgery; OHNS, otolaryngology, head \& neck surgery; OR, operating room.

Table 2. Disease Factors

\begin{tabular}{llllll}
\hline Factor & \multicolumn{1}{c}{$\mathbf{1}$} & \multicolumn{1}{c}{$\mathbf{2}$} & $\mathbf{3}$ & $\mathbf{4}$ & $\mathbf{5}$ \\
\hline $\begin{array}{c}\text { Nonoperative treatment } \\
\text { option effectiveness }\end{array}$ & None available & $\begin{array}{c}\text { Available, <40\% } \\
\text { as effective as } \\
\text { surgery }\end{array}$ & $\begin{array}{l}\text { Available, 40\% } \\
\text { to 60\% as } \\
\text { effective as surgery }\end{array}$ & $\begin{array}{c}\text { Available, 61\% } \\
\text { to 95\% as } \\
\text { effective as surgery }\end{array}$ & $\begin{array}{c}\text { Available, equally } \\
\text { effective }\end{array}$ \\
\hline $\begin{array}{l}\text { Nonoperative treatment } \\
\text { option resource/ } \\
\text { exposure risk }\end{array}$ & $\begin{array}{c}\text { Significantly } \\
\text { worse/not } \\
\text { applicable }\end{array}$ & Somewhat worse & Equivalent & Somewhat better & Significantly better \\
\hline $\begin{array}{l}\text { Impact of 2-wk delay in } \\
\text { disease outcome }\end{array}$ & $\begin{array}{c}\text { Significantly } \\
\text { worse }\end{array}$ & Worse & Moderately worse & Slightly worse & No worse \\
\hline $\begin{array}{l}\text { Impact of 2-wk delay in } \\
\text { surgical difficulty/ } \\
\text { risk }\end{array}$ & $\begin{array}{c}\text { Significantly } \\
\text { worse }\end{array}$ & Worse & Moderately worse & Slightly worse & No worse \\
\hline $\begin{array}{l}\text { Impact of 6-wk delay in } \\
\text { disease outcome }\end{array}$ & $\begin{array}{c}\text { Significantly } \\
\text { worse }\end{array}$ & Worse & Moderately worse & Slightly worse & No worse \\
\hline $\begin{array}{l}\text { Impact of 6-wk delay in } \\
\text { surgical difficulty/ } \\
\text { risk }\end{array}$ & $\begin{array}{c}\text { Significantly } \\
\text { worse }\end{array}$ & Worse & Moderately worse & Slightly worse & No worse \\
\hline
\end{tabular}

Table 3. Patient Factors

\begin{tabular}{|c|c|c|c|c|c|}
\hline Factor & 1 & 2 & 3 & 4 & 5 \\
\hline Age, $y$ & $<20$ & $21-40$ & $41-50$ & $51-65$ & $>65$ \\
\hline $\begin{array}{l}\text { Lung disease (asthma, COPD, } \\
\text { CF) }\end{array}$ & None & - & - & Minimal (rare inhaler) & $>$ Minimal \\
\hline Obstructive sleep apnea & Not present & - & - & Mild/moderate (no CPAP) & On CPAP \\
\hline CV disease (HTN, CHF, CAD) & None & Minimal (no meds) & Mild (1 med) & Moderate (2 meds) & Severe ( $\geq 3$ meds) \\
\hline Diabetes & None & - & Mild (no meds) & Moderate (PO meds only) & $>$ Moderate (insulin) \\
\hline Immunocompromised ${ }^{*}$ & No & & & Moderate & Severe \\
\hline $\begin{array}{l}\text { ILI symptoms (fever, cough, sore } \\
\text { throat, body aches, diarrhea) }\end{array}$ & None (Asymptomatic) & - & - & - & Yes \\
\hline $\begin{array}{l}\text { Exposure to known COVID-19 } \\
\text { positive person in past } 14 \text { days }\end{array}$ & No & Probably not & Possibly & Probably & Yes \\
\hline
\end{tabular}

Fig. 1 The Medically Necessary, Time-Sensitive (MeNTS) procedures scoring tool 


\section{Methods}

We developed a scoring tool 'MeNT-OS' (Medically Necessary and Time-Sensitive-Orthopaedic Surgery) consisting of variables that would reflect human and physical resource utilisation, surgical complexity, functional status of patients, as well as COVID-19 transmission risk (Fig. 2). A total of 13 unique variables were included and stratified into Surgical Factors and Disease Factors, scored on a three or five-point scale, for a total score range of 13-51 points. Higher numeric values were assigned to factors that would reflect greater resource utilisation, increased surgical morbidity, increased risk of COVID-19 transmission, and less adverse functional impact on patients. A higher overall score is, therefore, designed to correlate with lower surgical prioritisation.

\section{Modifications from the MeNTS Score}

The original MeNTS tool proposed by Prachand et al. consists of 21 variables stratified into three categories of Procedure, Disease and Patient factors, with each scored on a five-point scale to yield a cumulative score range of 21-105 points. Higher scores reflected lower prioritisation of cases as they signified poorer peri-operative patient outcomes, high resource utilisation and increased risk of COVID-19 transmission to the healthcare team. In the development of our Orthopaedic-specific scoring tool, we retained some variables present in the original MeNTS tool while excluding those that were impractical in the Orthopaedic setting. The rationale for exclusion of certain factors is detailed below.

\section{Factors Excluded, Modified, and Added}

Amongst Procedure Factors, we omitted 'Intubation Probability' as we found it to be challenging to determine objectively with the arbitrarily assigned answer stems. However, we recognised the effects of intubation on increased aerosolisation of airway secretions [8], as well as its potential effects on post-operative respiratory function. We felt this was represented adequately with 'Type of Anaesthesia Used' instead, with highest scores associated with the use of general anaesthesia involving intubation.

Our algorithm introduced another factor to evaluate the risk of COVID-19 transmission to the surgical team, based on the potential for aerosol generation. The use of certain surgical tools-namely, use of diathermy, pulse lavage, ultrasonic tools, and power tools or high speed burrs-has been shown to increase aerosol generation $[9,10]$; hence, higher scores were assigned to procedures which were predicted to require the use of these tools.

'Surgical Site' was removed from our scoring tool as none of the anatomical categories described were relevant for commonly performed Orthopaedic surgeries. In contrast to general surgical procedures, Orthopaedic procedures do not typically involve manipulation of the upper aerodigestive tract or the thorax, which are risk factors for airway secretion aerosolisation. In general, there have been no strong correlations between Orthopaedic surgical site (which are often in the peripheral joints) and post-operative respiratory function, with the notable exception of spine surgeries involving the prone position [11]. Even so, we felt that these risks were evaluated sufficiently with the other existing variables in our scoring system.

The variable 'Post-Operative ICU need' was better modified to 'Type of Inpatient Bed Required', with the assumption that admission to the high dependency ward or ICU would entail greater resource consumption.

Disease Factors were modified to be more specialty-centered. We proposed to estimate the impact of delayed surgery on 'functional outcome' rather than 'disease outcome' proposed originally, as functional outcomes are generally more clearly defined in the Orthopaedic setting, in addition to being a key practical consideration in the listing of most Orthopaedic surgeries (with the possible exception of oncologic surgeries). For ease of scoring, less variability was introduced in the scoring of these categories with a threepoint scale rather than a five-point scale.

Other modifications were made in the category of Patient Factors. We chose to use the ASA classification to serve as a surrogate measure for patient comorbidities and severity of systemic disease, thus removing the need to individually score age, cardiorespiratory diseases, diabetes, and immunocompromised status. This reduced the complexity of the scoring system while also ensuring that the principle of selecting patients with a higher likelihood of tolerating surgery was not compromised.

Two other Patient Factors-presence of influenza-like illness (ILI) symptoms, and exposure to known COVID19-positive persons within a 14-day period, were considered redundant and excluded as the presence of any of the above would have likely resulted in the cancellation of the surgery at our institution.

\section{Factors Retained}

We retained the other factors of Time in Operating Room, Anticipated Blood Loss, Surgical Team Size, and Estimated Length of Stay to serve as surrogate measures of anticipated 


\begin{tabular}{|c|c|c|c|c|c|}
\hline \multicolumn{6}{|l|}{ Surgical Factors } \\
\hline Variable & 1 & 2 & 3 & 4 & 5 \\
\hline $\begin{array}{l}\text { Operating room } \\
\text { time, } \min \end{array}$ & $\leq 30$ & $31-60$ & $61-120$ & $121-180$ & $\geq 181$ \\
\hline $\begin{array}{l}\text { Estimated blood } \\
\text { loss, ml }\end{array}$ & $\leq 100$ & $101-250$ & $250-500$ & $500-750$ & $\geq 751$ \\
\hline Type of anaesthesia & $\begin{array}{l}\text { Local } \\
\text { anaesthesia }\end{array}$ & Regional & $\begin{array}{l}\text { General } \\
\text { anaesthesia }\end{array}$ & & \\
\hline Surgical team size & 1 & 2 & 3 & 4 & $>4$ \\
\hline $\begin{array}{l}\text { Estimated length of } \\
\text { stay }\end{array}$ & Day Surgery & $\leq 23 \mathrm{hrs}$ & $24-48 \mathrm{hrs}$ & $48-72 \mathrm{hrs}$ & $\geq 4$ days \\
\hline $\begin{array}{l}\text { Type of bed } \\
\text { required }\end{array}$ & Day surgery & General ward & $\begin{array}{l}\text { High } \\
\text { dependency }\end{array}$ & ICU & \\
\hline ASA & 1 & 2 & 3 & 4 & 5 \\
\hline $\begin{array}{l}\text { Equipment used (1 } \\
\text { point for each) } \\
\text { - Diathermy } \\
\text { - Pulse lavage } \\
\text { - Ultrasonic tools } \\
\text { - Power tools/high } \\
\text { speed burrs }\end{array}$ & 1 & 2 & 3 & 4 & \\
\hline \multicolumn{6}{|l|}{ Disease Factors } \\
\hline Variable & 1 & 2 & 3 & & \\
\hline $\begin{array}{l}\text { Conservative } \\
\text { treatment } \\
\text { effectiveness }\end{array}$ & Non available & $\begin{array}{l}\text { Available, not } \\
\text { as effective as } \\
\text { surgery }\end{array}$ & $\begin{array}{l}\text { Available, } \\
\text { effective as } \\
\text { surgery }\end{array}$ & & \\
\hline $\begin{array}{l}\text { Impact on function } \\
\text { with } 2 \text { month delay } \\
\text { in surgery }\end{array}$ & $\begin{array}{l}\text { Significantly } \\
\text { worse }\end{array}$ & $\begin{array}{l}\text { Moderately } \\
\text { worse }\end{array}$ & $\begin{array}{l}\text { Slightly worse } \\
\text { or equal }\end{array}$ & & \\
\hline $\begin{array}{l}\text { Impact on surgical } \\
\text { difficulty/risk with } \\
2 \text { month delay }\end{array}$ & $\begin{array}{l}\text { Significantly } \\
\text { worse }\end{array}$ & $\begin{array}{l}\text { Moderately } \\
\text { worse }\end{array}$ & $\begin{array}{l}\text { Slightly worse } \\
\text { or equal }\end{array}$ & & \\
\hline $\begin{array}{l}\text { Impact on function } \\
\text { with } 6 \text { month delay } \\
\text { in surgery }\end{array}$ & $\begin{array}{l}\text { Significantly } \\
\text { worse }\end{array}$ & $\begin{array}{l}\text { Moderately } \\
\text { worse }\end{array}$ & $\begin{array}{l}\text { Slightly worse } \\
\text { or equal }\end{array}$ & & \\
\hline Impact on surgical & Significantly & Moderately & Slightly worse & & \\
\hline
\end{tabular}

Fig. 2 Modified MeNTS scoring tool for Orthopaedic Surgery-the "MeNT-OS" score

resource consumption. The Impact of Delay in Surgical Difficulty/Risk was also retained.

We then proceeded to test this scoring system retrospectively, with both postponed and completed Orthopaedic cases during the early COVID-19 pandemic period from February to May 2020. Scores were calculated and compared for a total of 69 completed and 49 postponed cases from sub-specialties of Adult Reconstruction, Spine, Sports, Foot and Ankle and Musculoskeletal Oncology (Tumour). A smaller sample of cases was used to evaluate the utility of the MeNTS score as a prioritisation tool for Orthopaedic surgeries.

\section{Results}

Our MeNT-OS scoring system identified a total of 13 factors that would contribute to triage and prioritisation of Orthopaedic procedures in the setting of the COVID-19 pandemic. 
These factors were divided into Surgical Factors (8 Factors) and Disease Factors (5 Factors).

A total of 118 Orthopaedic cases, consisting of 69 completed cases and 49 postponed cases, were used in the trial of our MeNT-OS scoring system. These cases were all performed at a single institution in Singapore during a 4-month period of the COVID-19 pandemic, from February to May 2020. The cases were drawn the caseload of five surgeons from the Orthopaedic sub-specialties outlined above. A breakdown of cases by subspecialty is provided (Fig. 3), with Sports, Spine, and Foot and Ankle accounting for a higher proportion of completed cases, and Adult Reconstruction a higher proportion of postponed cases.

The application of the modified scoring system to the completed cases resulted in scores ranging from 19 to 38 , with a mean of 31.3 and a median of 31 . The scores for postponed cases ranged from 25 to 41 , with a mean score of 32.6 and a median of 35 (Fig. 4a, b). Mann-Whitney $U$ test was used to assess the scoring system to compare scores of completed and postponed cases, and returned a statistically significant $p$ value of 0.0003 .

Among the Orthopaedic sub-specialties, higher mean scores for both completed and postponed cases were observed for cases from Adult Reconstruction and Spine, while scores for surgeries from Foot and Ankle, Sports, and Oncology were lower in comparison (Fig. 4c). Postponed surgeries from Adult Reconstruction, Foot and Ankle, and Spine sub-specialties had higher scores compared to completed cases from the same specialty, whereas scores for Oncology and Sports were marginally lower for postponed cases. Using the Mann-Whitney U test, our scoring system was further validated for Spine and Adult Reconstruction subspecialty cases with $p$ values of 0.006 and 0.003 , respectively. We were not able to obtain statistically significant $p$ values for the sub-specialties of Sports, Foot and Ankle and Tumour.

A sample of 26 cases, consisting of 9 completed and 17 postponed cases from a single surgeon were also evaluated using the MeNTS tool for a trial of validation. Scoring with the MeNTS tool resulted in a mean score of 58.3 for completed cases and 55.2 for postponed cases, with a $p$ value of 0.112 rendering it statistically not significant at a $95 \%$ confidence interval.

Attempts were made to study reliability of our dataset using Cronbach's Alpha, with computed values of 0.58 from data for completed cases, and 0.64 for postponed cases suggestive of moderate internal consistency of data.

\section{Discussion}

The resumption of elective Orthopaedic surgery during the COVID-19 period is likely to occur in a phased manner, and will require surgeons to prioritise procedures in order to account for manpower and resource limitations that will lower surgical capacities. Surgeons, hospitals, and healthcare systems have not approached this uniformly, with many continuing to rely on individual judgement to decide which surgeries should be performed. Our institution, which is incidentally at the epicenter of the response to the COVID-19 pandemic in Singapore, has employed a department-focused approach that prioritises cases based on surgical indication and urgency. In specific, surgical departments are asked to prioritise their delayed cases and submit them to a multi-disciplinary committee for approval; once approved, surgeons/ departments are granted time to perform these surgeries in pre-allocated operating theatres.
Fig. 3 Breakdown of postponed and completed surgeries by subspecialty

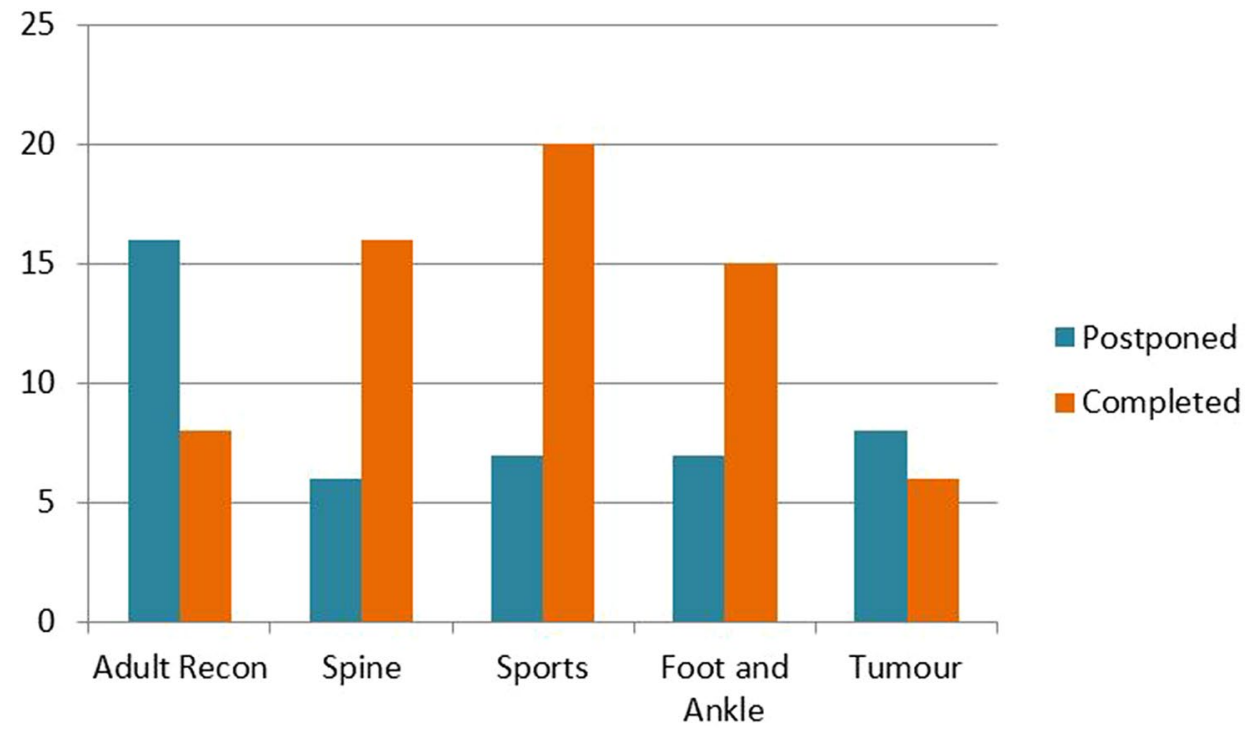


Fig. 4 a Comparison of MeNTOS scores illustrating higher mean and median scores for postponed cases. b Distribution of scores for postponed and completed surgeries, and identification of potential cut-off point based on current data. c Comparison of average MeNTOS scores between Orthopaedic sub-specialties
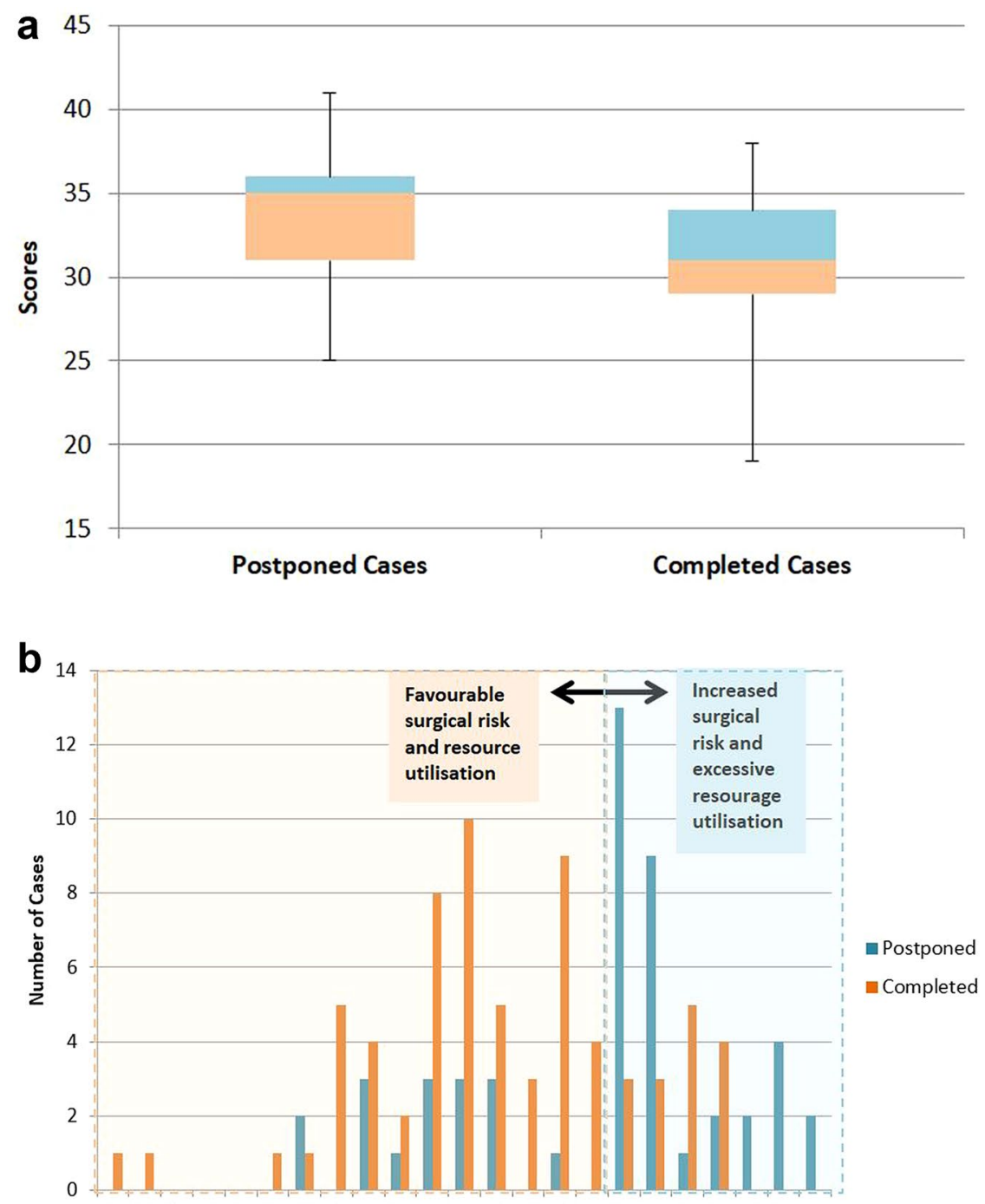

$1920 \quad 2122 \quad 23242526 \quad 27282930 \quad 31 \quad 32 \quad 33 \quad 34 \quad 35 \quad 36 \quad 37 \quad 38 \quad 3940 \quad 41$ MeNTOS Score

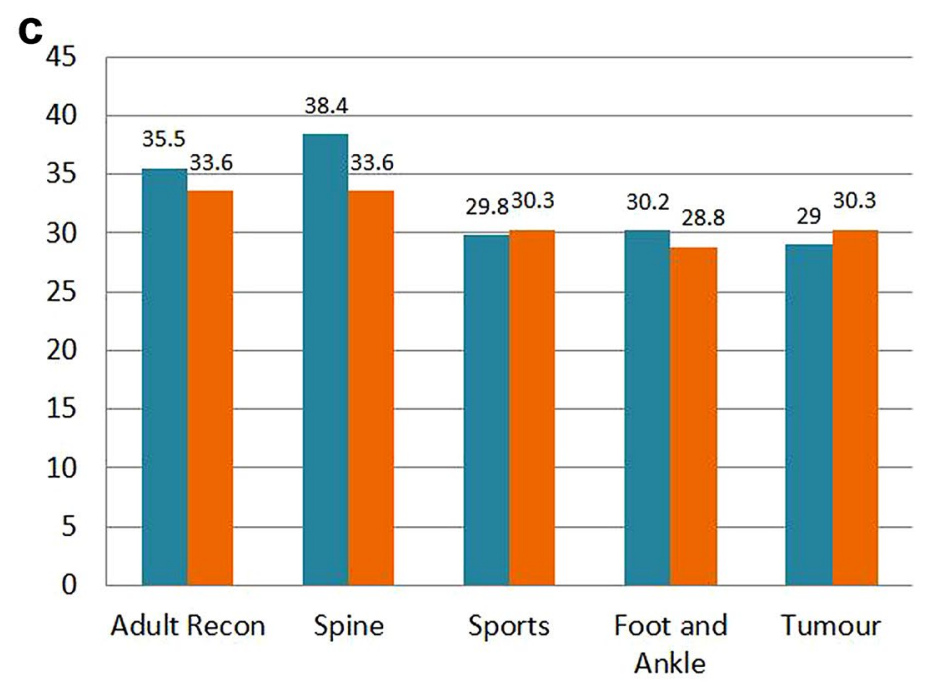

Postponed a Completed 
Our aim was to introduce a measure of objectivity into this process with the development of a specialty-centric scoring system.

The use of our MeNT-OS scoring system resulted in higher mean scores for postponed cases compared to completed cases, as well as higher median, 25th and 75th percentile scores (Fig. 4a). These differences were statistically significant and were internally validated using a sample of 69 completed and 49 postponed cases. These results showed concordance with the ad hoc decisions made before the scoring system was used, with the lower scores for completed cases suggesting a more favourable risk-benefit ratio for being performed as compared to the postponed cases.

Among the Orthopaedic surgery sub-specialties, statistically significant differences were observed in the comparison of scores for completed and postponed cases from adult reconstruction and spine surgery. As these two subspecialties account for most Orthopaedic patients requiring inpatient admission after elective surgeries (74\% of inpatient admissions amongst completed cases in our cohort), the MeNT-OS shows promise in helping surgeons prioritise cases appropriately to ensure optimal utilisation of hospital resources.

Although marginally lower scores for postponed cases were observed in the sub-specialties of Sports and Tumour, these differences were not proven to be statistically significant with $p$-values of greater than 0.05 .

While we noted there to be a wide distribution of overlapping scores for both completed and postponed cases, we observed a mean score of 31.3 for completed cases and 32.6 for postponed cases, and median scores of 31 and 35 , respectively. With an arbitrary cut-off score of 34 derived from these values (above which cases are recommended to consider deferment of surgery) (Fig. 4b), we were able to identify $67 \%$ of postponed cases and $78 \%$ of completed cases retrospectively. Although the accuracy of such a cutoff point is limited by the number of overlapping scores, we believe that such a threshold would be dynamic, and should be adjusted based on local considerations, especially for cases with scores close to the cut-off point.

A number of other scoring systems and algorithms have been proposed to guide decision making for prioritisation of surgeries during the COVID-19 period. These include broadly applicable tools such MeNTS [7], designed for use on a wide range of surgical specialties, as well as specialtyspecific tools such as the Johns Hopkins Gynaecologic Prioritisation System [12] (JH-GPS). The Spine Urgency Score is another such tool [13], jointly developed by neurosurgeons and Orthopaedic spine surgeons for prioritising spine surgery cases in resource-limited settings. A modification of the MeNTS score for use in the paediatric population has also been described [14].
However, our attempted validation of the MeNTS scoring tool for Orthopaedic Surgery, with retrospective scoring of postponed and completed cases, suggested that the score would have limited applicability for Orthopaedics in its original format. This was evidenced by the fact that completed cases were assigned higher overall scores than postponed cases, a result that contradicted the notion that patients assigned lower scores should be prioritised for surgery. Although our sample size was small and not statistically significant, these preliminary results further highlighted the need for a scoring system tailored for Orthopaedic use.

From our preliminary evaluations, we were able to identify a number of advantages of our scoring system as compared to the MeNTS tool. Our 'MeNT-OS' system was designed to be specialty-centric with the inclusion of several factors that were more relevant to Orthopaedic practice, including considerations for the use of aerosol-generating tools commonly used in Orthopaedics, as well as the impact of delayed surgery on the functional status of the patient. Conversely, factors that were considered less applicable for use in Orthopaedic practice were excluded as detailed.

These purported advantages were validated in our evaluations with both our own scoring system as well as a trial of the MeNTS tool for Orthopaedic surgery.

The MeNT-OS scoring tool has several limitations. As with the MeNTS tool and other similar scoring systems published for this purpose, equal weightage was given to all factors in our scoring. It is thus inevitable that certain factors may be assigned disproportionate weightage; this may need to be revised once more data is available on peri-operative outcomes in the COVID-19 pandemic. Despite efforts to design a scoring tool that was as objective as possible, there may still be significant subjectivity in scoring certain factors such as the functional impact of delayed surgery, or the effectiveness of conservative treatment. These factors were also identified as possible contributors to the higher scores seen for completed surgeries, compared to postponed surgeries, in the Sports and Tumour services.

As a preliminary study involving a relatively arbitrary modification of the MeNTS scoring system, our study was primarily aimed at assessing the relative concordance of the ad hoc review process, and was not intended to be an in-depth study to assess validity and reliability of the MeNT-OS score in a true sense. Reliability analysis of our data with Cronbach's Alpha revealed a sub-optimal level of internal consistency within our data for completed and postponed cases, with values of 0.58 and 0.64 , respectively. These values reflect a moderate degree of reliability at best, and may be explained by (a) heterogeneity of factors in the scoring system, with a mixture of quantitative and qualitative factors and (b) polytomous response options for qualitative factors, and (c) poor 
inter-relatedness between items in the scoring tool, all which may have led to underestimation of the true reliability of the MeNT-OS scoring data. Overall reliability may be improved in future studies by identifying factors with a low correlation to the final outcome and excluding them from the scoring tool.

Lastly, we were unable to ensure equal representation of all subspecialty cases, and were also limited to the cases of five surgeons at our institution, which reduced our overall sample size and ability to utilise more robust methods (such as ROC curve analysis/logistic regression modelling) to determine a 'cut-off score' for the MeNT-OS tool. Future studies involving larger sample sizes are planned for this purpose; such techniques would also enable the identification of more influential factors within the MeNT-OS tool, and facilitate further refinement of the scoring system by assigning appropriate weightage to these factors.

\section{Conclusion}

As the global COVID-19 pandemic continues to evolve, planning for the resumption of elective surgeries is underway in many countries. However, a return to pre-pandemic volumes of elective surgeries is unlikely for a significant period of time, pressuring hospitals and healthcare systems to select surgeries judiciously, to ensure the most efficient use of limited resources, reduce risk of COVID-19 transmission, while also maximising surgical benefits for patients.

We propose the use of a scoring system ('MeNT-OS'), based on a modification of the MeNTS tool, for triage and prioritisation of Orthopaedic surgeries to be performed during the COVID-19 pandemic period. A trial of the MeNTOS system, using data from our institution, has offered promising preliminary results, and offers an objective and systematic approach that is geared towards Orthopaedic procedures. We believe this scoring tool can provide Orthopaedic surgeons a safe and equitable approach to making difficult decisions on prioritisation of surgery during the COVID-19 period, and possibly, other resource-limiting situations in the future.

Funding There is no funding source.

\section{Compliance with Ethical Standards}

Conflict of interest The authors declare that they have no conflict of interest.

Ethical approval This article does not contain any studies with human participants or animals performed by any of the authors.
Informed consent Not applicable to this study.

\section{References}

1. Ministry of Health. (2020). Comprehensive Medical Strategy for COVID-19. https://www.moh.gov.sg/news-highlights/details/ comprehensive-medical-strategy-for-covid-19. Accessed 18 June 2020

2. Bedard, N. A., Elkins, J. M., \& Brown, T. S. (2020). Effect of COVID-19 on hip and knee arthroplasty surgical volume in the United States. Journal of Arthroplasty, 35(7), 45-48. https://doi. org/10.1016/j.arth.2020.04.060

3. Mouton, C., Hirschmann, M. T., Ollivier, M., Seil, R., \& Menetrey, J. (2020). COVID-19-ESSKA guidelines and recommendations for resuming elective surgery. Journal of Experimental Orthopaedics, 7(1), 28. https://doi.org/10.1186/s40634-020-00248-4

4. Oussedik, S., Zagra, L., Shin, G. Y., D’Apolito, R., \& Haddad, F. S. (2020). Reinstating elective orthopaedic surgery in the age of COVID-19. The Bone and Joint Journal, 102-B(7), 807-810. https://doi.org/10.1302/0301-620X.102B7.BJJ-2020-0808

5. American College of Surgeons. (2020). Joint Statement: Roadmap for Resuming Elective Surgery after COVID-19 Pandemic. https:// www.facs.org/covid-19/clinical-guidance/roadmap-elective-surge ry. Accessed 10 June 2020

6. Royal College of Surgeons of England. (2020). Recovery of surgical services during and after COVID-19. https://www.rcseng.ac. uk/coronavirus/recovery-of-surgical-services. Accessed 10 June 2020

7. Prachand, V. N., Milner, R., Angelos, P., Posner, M. C., Fung, J. J., Agrawal, N., Jeevanandam, V., \& Matthews, J. B. (2020). Medically necessary, time-sensitive procedures: scoring system to ethically and efficiently manage resource scarcity and provider risk during the COVID-19 pandemic. Journal of the American College of Surgeons, 231(2), 281-288. https://doi.org/10.1016/j. jamcollsurg.2020.04.011

8. Tran, K., Cimon, K., Severn, M., Pessoa-Silva, C. L., \& Conly, J. (2012). Aerosol generating procedures and risk of transmission of acute respiratory infections to healthcare workers: a systematic review. PLoS ONE, 7(4), e35797. https://doi.org/10.1371/journal. pone. 0035797

9. Simpson, A. H. R. W., Dall, G., \& Haas, J. G. (2020). COVID-19: potential transmission through aerosols in surgical procedures and blood products. Bone and Joint Research, 9(4), 200-201. https:// doi.org/10.1302/2046-3758.94.BJR-2020-0130

10. Raghavan, R., Middleton, P. R., \& Mehdi, A. (2020). Minimising aerosol generation during orthopaedic surgical procedures-current practice to protect theatre staff during Covid-19 pandemic. Journal of Clinical Orthopaedics and Trauma, 11(3), 506-507. https://doi.org/10.1016/j.jcot.2020.04.024

11. Manna, E. M., Ibraheim, O. A., Samarkandi, A. H., Alotaibi, W. M., \& Elwatidy, S. M. (2005). The effect of prone position on respiratory mechanics during spinal surgery. Middle East Journal of Anaesthesiology, 18(3), 623-630.

12. Christianson, M. S., Martin, S., Lawson, S. M., Esguerra, C., Lippitt, M. H., Wu, H., Handa, V. L., Satin, A. J., \& Fader, A. N. (2020). Patient-centered, gynecology-specific prioritization of nonurgent surgeries during the COVID-19 pandemic: proposal of a novel scoring system. Journal of Minimally Invasive Gynecology, 27(6), 1429-1433. https://doi.org/10.1016/j.jmig.2020.05. 026

13. Sciubba, D. M., Ehresman, J., Pennington, Z., et al. (2020). Scoring system to triage patients for spine surgery in the setting of 
limited resources: application to the coronavirus disease 2019 (COVID-19) pandemic and beyond. World Neurosurg, 140, 373 380. https://doi.org/10.1016/j.wneu.2020.05.233

14. Slidell, M. B., Kandel, J. J., Prachand, V., Baroody, F. M., Gundeti, M. S., Reid, R. R., Angelos, P., Matthews, J. B., \& Mak, G. Z. (2020). Pediatric modification of the medically necessary, time-sensitive scoring system for operating room procedure prioritization during the COVID-19 pandemic. Journal of the American College of Surgeons, 231(2), 205-215. https://doi.org/ 10.1016/j.jamcollsurg.2020.05.015

Publisher's Note Springer Nature remains neutral with regard to jurisdictional claims in published maps and institutional affiliations. 